Check for updates

Cite this: RSC Adv., 2017, 7, 56771

Received 10th October 2017 Accepted 25th November 2017

DOI: 10.1039/c7ra11142h

rsc.li/rsc-advances

\section{Incorporated $\alpha$-amylase and starch in an edible chitosan-procyanidin complex film increased the release amount of procyanidins}

\author{
Dongliang Zhang, Lijun Jiang, Jinhuan Zong, Shanfeng Chen, Chengye Ma \\ and Hongjun $\mathrm{Li}$ (iD) *
}

The inclusion of bioactive substances improved the characteristics of chitosan film or adds new functions to it. Chitosan dissolution is a dilemmatic problem because of the low $\mathrm{pH}$ of edible solvents and moderate $\mathrm{pH}$ of inedible solvents. Procyanidins, $\alpha$-amylase and starch were added in the film to enhance the antioxidant ability. Sodium bicarbonate was also employed to adjust the $\mathrm{pH}$ of acetic acid solution (solvent). Constituent optimisation of the film-forming solution including the $\mathrm{pH}$ of solutions with different amounts of sodium bicarbonate, activity of $\alpha$-amylase at different $\mathrm{pH}$ and addition of appropriate amounts of the three main ingredients was performed. The results showed that the solvent $\mathrm{pH}$ should be more than 4 . The released amount of reducing sugar (starch hydrolyzate) increased with the increase in the amount of enzyme addition. $\alpha$-Amylase exhibited a more significant effect than procyanidins, increasing the amount of procyanidins. Full-wavelength scanning, optical test, scanning electron microscopy, X-ray diffraction (XRD), infrared (IR) and differential scanning calorimetry (DSC) were performed to measure the film's characteristics. Even the absorbance peak of procyanidins at $280 \mathrm{~nm}$ was increased, following its increasing addition amount; the optical values showed no significant difference. Chitosan film containing starch, $\alpha$-amylase and procyanidins (CSAPW) had a smoother surface than others. Moreover, the micropores observed on CSAPW can be induced by starch hydrolysis in water immersion. The results of $X$-ray diffraction (XRD), IR and DSC suggested that water immersion provided the environment for enzymes to hydrolyse the starch. In addition, the hydrolysis function induced the destruction of CSAPW'S crystal structure, the change of vibration of hydrogen between chitosan, starch, procyanidins, water and the variation of water evaporation temperature.

\section{Introduction}

Chitosan is an ideal fresh-keeping material for food due to its characteristics including edibility, nontoxicity, film formation and antimicrobial activities. ${ }^{\mathbf{1 - 3}}$ Chitosan-incorporated films are attractive for research and applications, such as the shelf-life extension of sliced fresh red meats by low-density polyethylene-incorporated chitosan films, ${ }^{4}$ maintenance of the visual appearance, taste and even the overall quality of strawberries by chitosan-beeswax films. ${ }^{5}$ Compounds that can improve films' mechanical or bioactive properties have been used in the preparation and application of the chitosan film to enhance its performance. ${ }^{6,7}$ Starch, one of the most common foods and an edible ingredient, has also been used in preparing the chitosan film. The starch-incorporated chitosan film acquired preferable elongation at break-point and water vapour transmission rate by the interaction between the hydroxyl

School of Agricultural Engineering and Food Science, Shandong University of Technology, No. 266 Xincun Road, Zhangdian District, Zibo, Shandong Province, China. E-mail: Hongjunli1351@hotmail.com; Tel: +86-5332786382 ext.88 groups of starch and the amino groups of chitosan, thus possessing also an outstanding antibacterial activity ${ }^{8,9}$ Some antioxidative substances or bioactive compounds such as essential oil, ferulic acid, maqui berry and polyphenols from thyme extracts can be added to the starch-incorporated film to limit its disadvantages. ${ }^{7,10-12}$ Based on the incorporation methods, sustained-release chitosan film with medicine release or enhanced fresh-keeping ability ${ }^{\mathbf{1 3 - 1 6}}$ can be developed.

Although the chitosan complex film can exhibit multiple functions depending upon the incorporation method, the use of chitosan has been seriously restricted because of its poor solubility. Chitosan can be only dissolved in some specific organic acids and a few inorganic solvents, ${ }^{17}$ which led to a number of studies on chitosan dissolution. Various aqueous solutions and chitosan modifications were investigated to fix this problem. ${ }^{18,19}$ However, modification made chitosan inedible, and aqueous solutions were usually alkaline, acidic or toxic. Unstable compounds such as enzyme and certain antioxidants lose their activities in extreme $\mathrm{pH}$.

Procyanidins, present in foods such as apples, berries, cocoa, grapes and wine, are the second most abundant natural 
phenolic compounds after lignin. ${ }^{20}$ They exhibit multiple physiological activities, such as antioxidant, antimicrobial, antiinflammatory, ant-carcinogenic and anti-hypertensive activities, and have been studied extensively in recent years. ${ }^{21-23}$ In particular, the strong radical scavenging ability and highantioxidant capacity of procyanidins were determined by in vitro tests; $;^{24,25}$ nevertheless, only oligomeric procyanidins (up to trimeric compounds) were bioavailable and resorbed in the intestine. $^{20}$

Therefore, procyanidins were added into the chitosan film to endow its antioxidant ability. Starch and $\alpha$-amylase were also employed in the film preparing process to increase the release rate of procyanidins by starch hydrolysis. Considering the dilemmatic problem that chitosan was dissolved in low $\mathrm{pH}$ of an edible solvent (such as acetic acid) and moderate $\mathrm{pH}$ of an inedible solvent, ${ }^{26,27}$ a method was developed to adjust the $\mathrm{pH}$ of the chitosan-acetic acid solution and afforded moderate enzyme activity.

\section{Materials and methods}

\subsection{Materials}

Medium molecular weight chitosan (CAS, 9012-76-4, deacetylation degree $>90 \%$, Bide Biotechnology Ltd., Shanghai China), procyanidins (CAS, 4852-22-6, Baishun Biotechnology Ltd., Tianjin, China), $\alpha$-amylase (CAS, 9001-19-8, Puyihua Biotechnology Ltd., Beijing, China), ABTS (CAS, 30931-67-0, Meilunbio Biotechnology Ltd., Dalian, China) and starch (CAS, 9005-25-8, Alading Ltd., Shanghai, China) were used in this study.

\subsection{Film formation}

2.2.1 Pre-preparation solution. Chitosan ( 1 g) was dispersed in $30 \mathrm{~mL}$ water with an electromagnetic stirrer until the homogeneous chitosan dispersion formed. Acetic acid (10 $\mathrm{mL}$ ) was mixed with the chitosan solution and shaken for $1 \mathrm{~min}$ to dissolve the chitosan until the solution showed a transparent color. Subsequently, $10 \mathrm{~mL}$ water, certain volumes $(1,3,5,7$ and $9 \mathrm{~mL})$ of sodium bicarbonate $\left(0.5 \mathrm{~mol} \mathrm{~L}^{-1}\right)$ and $1 \mathrm{~mL}$ glycerol were blended with the homogenised solution, in sequence, with 5 min stirring intervals. Finally, water was added to obtain a total volume of $100 \mathrm{~mL}$, and the solution was vacuum degassed for five minutes.

2.2.2 Film-forming solution. Pre-preparation solution $(30$ $\mathrm{mL}$ ) was mixed with certain volumes $(1,3,5,7$ and $9 \mathrm{~mL})$ of procyanidin solution (1\%), starch (1\%) and $\alpha$-amylase $(1 \%)$ in sequentially with 5 min stirring intervals following the addition of each solution. After vacuum degassing, film formation was performed following the modified procedures described by Clara Pastor. ${ }^{28}$ Film was obtained by casting the film-forming solution into a plastic plate $(9 \mathrm{~cm}$ diameter $)$ and drying at $40{ }^{\circ} \mathrm{C}$ for $48 \mathrm{~h}$ in the dark.

\subsection{Constituent optimisation of film-forming solution}

2.3.1 $\mathrm{pH}$ change of film-forming solution during drying. Pre-preparation solutions were made following the description in Section 2.2.1; after vacuum degassing, it was dried at $40^{\circ} \mathrm{C}$ in a $250 \mathrm{~mL}$ beaker. The $\mathrm{pH}$ of the solution was measured at residual volumes of 100, 70, 40 and $10 \mathrm{~mL}$ (induced by the water evaporation).

2.3.2 Enzyme activity of $\alpha$-amylase at different $\mathrm{pH}$. Sodium acetate-acetic acid buffer solution and phosphate buffer solution $(\mathrm{pH}=3,4,5,6$ and 7$)$ containing $1 \% \alpha$-amylase were stored at $40{ }^{\circ} \mathrm{C}$ for 24,48 and $72 \mathrm{~h}$. Up to $1 \mathrm{~mL}$, the abovementioned solution was taken every $24 \mathrm{~h}$ to perform the following trial. The enzyme solution $(1 \mathrm{~mL})$ was mixed with equal volumes of starch (1\%) and kept at $60{ }^{\circ} \mathrm{C}$ for $10 \mathrm{~min}$; after cooling, $1 \mathrm{~mL} \mathrm{3,5-}$ dinitrosalicylic acid was added and the absorbance was measured by the 3,5-dinitrosalicylic acid assay. ${ }^{29}$ The absorbance representing the concentration of reduced sugar was used to evaluate the enzyme activity of hydrolysis.

2.3.3 Optimisation of starch content. Pre-preparation solutions (30 mL) containing $2 \mathrm{~mL} \alpha$-amylase (1\%) were each mixed with $0,1,2,3,4$ and $5 \mathrm{~mL}$ starch solution (1\%). After drying for $24 \mathrm{~h}$ at $40{ }^{\circ} \mathrm{C}$, the film was taken and submerged in $30 \mathrm{~mL}$ water; then, $1 \mathrm{~mL}$ solution was taken at 1,3 and 5 days and blended with $0.5 \mathrm{~mL} 3,5$-dinitrosalicylic acid. Absorbance detection using the 3,5-dinitrosalicylic acid assay was performed at last. The absorbance representing the concentration of reduced sugar was used to evaluate the hydrolysis degree of starch.

2.3.4 Standard curve of procyanidins. The absorbance of different concentrations of procyanidins solutions (dissolved in water) was determined by a spectrophotometer at $280 \mathrm{~nm}$ to establish a standard curve. ${ }^{30}$

2.3.5 Determination of procyanidins and $\alpha$-amylase content. Pre-preparation solution (30 mL) mixed with 1, 2, 3, 4 and $5 \mathrm{~mL}$ of procyanidin solution (1\%), $4 \mathrm{~mL}$ starch $(1 \%)$ and $2 \mathrm{~mL} \alpha$-amylase (1\%) was used to investigate the optimum addition volume of procyanidins in film. The same volume of the pre-preparation solution was mixed with $0,1,2,3,4$ and $5 \mathrm{~mL}$ of $\alpha$-amylase (1\%), $4 \mathrm{~mL}$ starch (1\%) and $4 \mathrm{~mL}$ procyanidin solution $(1 \%)$ in the optimisation trial of the $\alpha$-amylase addition amount. After drying for $48 \mathrm{~h}$ at $40{ }^{\circ} \mathrm{C}$ (following the description in Section 2.2.2), the film was taken and submerged in $30 \mathrm{~mL}$ water. Lixivium was taken at 1 and 7 days later and procyanidin content was detected. Films, along with the lixivium, were boiled at $95{ }^{\circ} \mathrm{C}$ for $15 \mathrm{~min}$ to determine their release amount under high temperature.

\subsection{Optical properties}

2.4.1 Colour coordinate. Colourimetry (CM-3600A, Konica Minolta, Japan) and ultraviolet-visible spectrometry (UV2102PCS, Unico Instrument Ltd., China) were employed to determine the optical properties of the film. The central area and the four areas around it were selected in this trial, and the total colour difference $(\Delta E)$ was calculated as follows: ${ }^{31}$

$$
\Delta E=\sqrt{\left(L^{*}\right)^{2}+\left(a^{*}\right)^{2}+\left(b^{*}\right)^{2}} .
$$

2.4.2 Full-wavelength scanning. The films were cut to fit the cuvette and attached on the inner side near the light source 
(blanking with empty cuvette), and absorbance was recorded at every $12 \mathrm{~nm}$ wavelength interval from $200 \mathrm{~nm}$ to $992 \mathrm{~nm}$.

\subsection{Scanning electron microscopy}

Four types of films were detected in this trial. The first contained chitosan starch, $\alpha$-amylase and procyanidins (CSAP). The second was formed by chitosan, starch and procyanidins (CSP). The third was made by chitosan, starch, $\alpha$-amylase and procyanidins and immersed in water for 7 days (CSAPW), and the last film constituted chitosan, starch, and procyanidins and immersed in water for 7 days (CSPW). Scanning electron microscopy (SEM) was applied in all these films.

\subsection{X-ray diffraction detection}

Pre-preparation solution was dried to prepare the chitosan film, the chitosan starch film containing starch (CS) and the chitosan-starch- $\alpha$-amylase film (CSA) produced using starch and $\alpha$ amylase. Chitosan, starch, $\alpha$-amylase, procyanidins, chitosan film, CS, CSA, CSAP, CSP, CSAPW and CSPW were used in the XRD measurements.

The samples were investigated with an X-ray diffractometer (D8-ADVANCE, Bruker AXS, Germany) equipped with a copper tube operated at $35 \mathrm{kV}$ and $30 \mathrm{~mA}$ with $\mathrm{Cu}$ radiation of $0.154 \mathrm{~nm}$ wavelength. Diffractograms were obtained by scanning from $3^{\circ}$ to $50^{\circ}$ at a rate of $0.5^{\circ} \mathrm{min}^{-1}$ with a step size of $0.02 .^{32}$

\subsection{Film stability determination by Fourier transform infrared spectroscopy}

The samples investigated via XRD were also investigated by Fourier transform infrared spectroscopy (FT-IR). The FT-IR spectra of the samples were recorded using a Nicolet 5700 spectrophotometer (Thermo Nicolet 5700, USA). The powdered samples were mixed separately with an analytical grade $\mathrm{KBr}$ and then pressed onto discs. The spectra of the samples were recorded in the region of $4000-400 \mathrm{~cm}^{-1}$, with a total of 32 scans. $^{33}$

\subsection{Differential scanning calorimetry analysis}

The samples studied via SEM were used to investigate the thermodynamic property by differential scanning calorimetry (DSC) in a TA Q100-DSC (USA) calorimeter. The films (100 mg) were weighted and heated from $10{ }^{\circ} \mathrm{C}$ to $140{ }^{\circ} \mathrm{C}$ at $10{ }^{\circ} \mathrm{C} \mathrm{min}{ }^{-1}$ under nitrogen atmosphere $;^{34}$ an empty pan was used to adjust the TA Q100-DSC (USA) calorimeter.

\section{Results and discussion}

\subsection{Optimisation of film-forming solution constituent}

Following the increase of sodium bicarbonate, the $\mathrm{pH}$ of filmforming solutions rose at a range from 4.15 to 4.45 at the beginning (100 $\mathrm{mL}$ residual volume). The maximum $\mathrm{pH}$ range was from 5.01 to 5.71 at the end of drying $(10 \mathrm{~mL}$ residual volume) (Fig. 1A). Acetic acid volatilisation and the increased
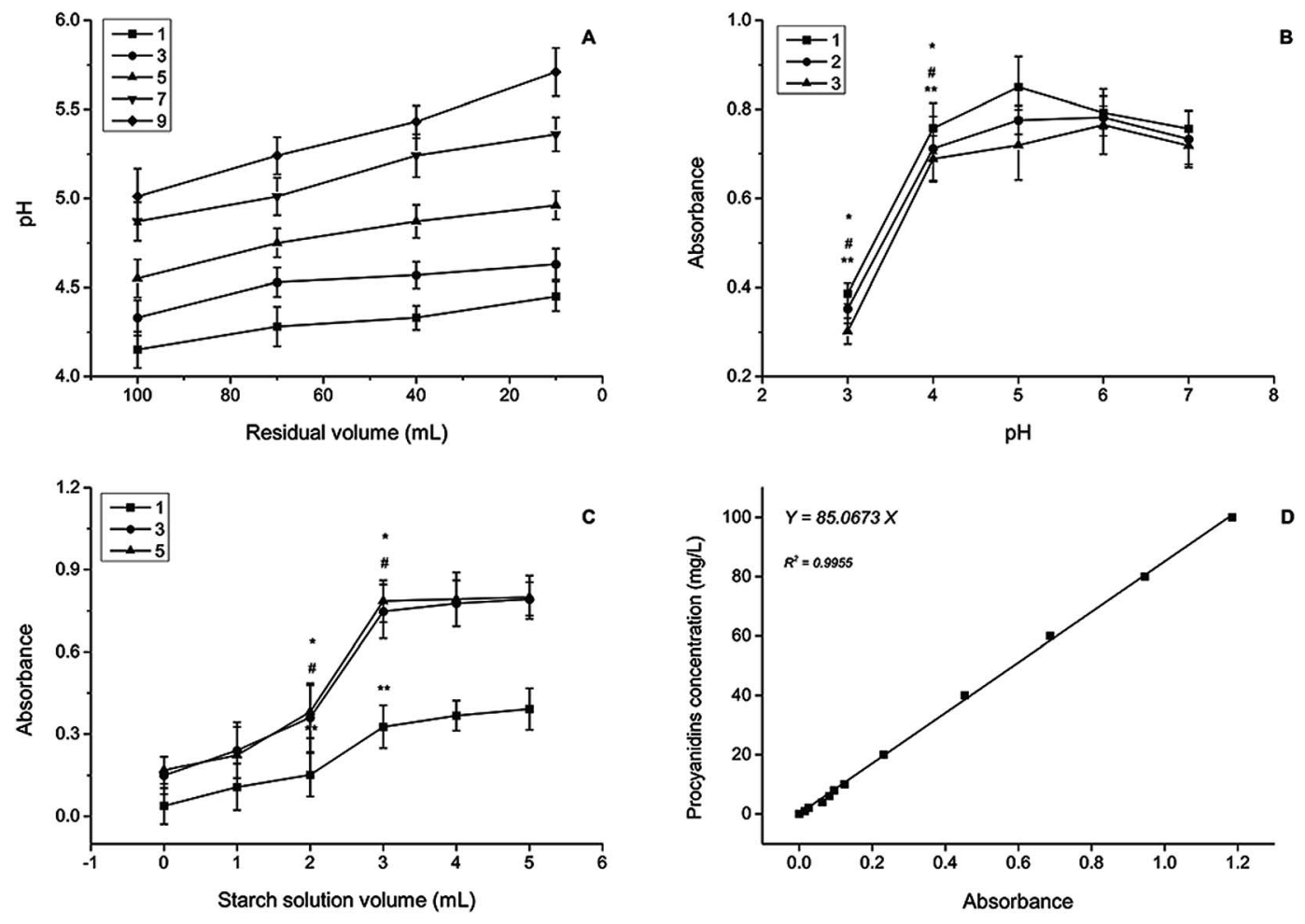

Fig. 1 Constituent optimization of film-forming solution. (A) pH change of film-forming solution in the drying process. Lines of 1, 3, 5, 7 and 9 are the addition volume of sodium bicarbonate solution $(\mathrm{mL})$. (B) Enzyme activity of $\alpha$-amylase at different $\mathrm{pH}$ and storage time. Lines of 1,2 and 3 are the film immersion time (days). (C) Optimization of starch content. Lines of 1, 3 and 5 are the film immersion time (days). (D) Standard curve of procyanidins. Same symbol represents significantly different values at $p \leq 0.05$. 
concentration of sodium acetate accompanying the water evaporation elevated the solution $\mathrm{pH}$. The low $\mathrm{pH}(\mathrm{pH}=3)$ significantly inhibited the enzyme activity at the chasing days with minimal difference between 24,48 and 72 h storage. After $24 \mathrm{~h}$ storage, the enzyme activity displayed the highest value at pH 5 and showed a decreased value at $\mathrm{pH}$ 7. No significant difference was observed between the enzyme activity at $\mathrm{pH}=4$, 5, 6 and 7 (Fig. 1B).

Starch solution with $3 \mathrm{~mL}$ addition in all of the three chasing days showed remarkable increase of reducing sugar content (Fig. 1C). Long-time immersion did not benefit the release of reducing sugar (starch hydrolysis) accounting for the amount of reducing sugar at 3 days approximated at 5 days, specifying that $\alpha$-amylase presented its function within 3 days. Enzyme as a type of protein containing hydroxyls, amino, and carboxyl can be immobilised by the interlinkage between the polar groups of chitosan and enzyme. ${ }^{35,36}$ Interlinkage between starch and protein also played an important part in restricting the movement of starch. ${ }^{37}$

Procyanidin solutions (concentration range from $0 \mathrm{mg} \mathrm{L}^{-1}$ to $100 \mathrm{mg} \mathrm{L}^{-1}$ ) were determined by a spectrophotometer and the standard curve was established with $R^{2}=0.9955$ (Fig. 1D). The film with more procyanidins maintained a high release amount, and no significant difference was observed between the procyanidin release amount at 1 and 7 days later for the groups with the same volume of procyanidin addition (Fig. 2A). In general, films with high procyanidin addition released more procyanidins with $3 \mathrm{~mL}$ as the turning point.

More procyanidins release was observed at the 7 day group when the $\alpha$-amylase addition amount was more than $3 \mathrm{~mL}$ (Fig. 2B). Starch hydrolysis destroyed the chainlike structure of starch and the network formed by the linkage between chitosan and starch facilitated the escape of procyanidins. Boiling enhanced the hydrolysis near the optimum temperature of $\alpha$ amylase at the $5 \mathrm{~mL}$ addition of procyanidins solution. Other groups demonstrated a decreased release amount. Procyanidins including polymers (four or more catechines) representing a group of condensed flavan-3-ols can be destroyed under high temperature. ${ }^{38-40}$

\subsection{Optical properties}

The absorption peaks of five films located approximately from $250 \mathrm{~nm}$ to $400 \mathrm{~nm}$ were elevated following the increase of procyanidin addition, indicating the absorption peak of procyanidins (Fig. 3A). ${ }^{30}$ The peaks identified near $450 \mathrm{~nm}$ could represent another type of procyanidins, such as the procyanidins B2. ${ }^{41}$ The values of $\Delta E$ for five films decreased following the increase in procyanidin addition with the same trends as $L^{*}$ that represented the colour lightness, suggesting that procyanidins decreased the film transparency (Fig. 3B). ${ }^{42}$ The colour parameter of $a^{*}$, which is the index of the red and green, indicated that the procyanidins show their red colour in films and a strong red colour was found in high procyanidin addition. ${ }^{43}$

\subsection{Morphology of films}

Cracks formed by drying occurred in CSAP and CSP films; wide cracks were observed on CSP and thin cracks on CSAP (arrowheads in CSP and CSAP of Fig. 4). Starch hydrolysed by $\alpha$ amylase in film drying produced monosaccharides, oligosaccharides and polysaccharides that probably formed a tighter link than the starch. Enzyme as a type of protein could contribute to the tensile strength (elasticity) and reduce the breaking of film. ${ }^{44}$ The starch-chitosan film did not have better mechanical properties than this chitosan film; thus, the starch containing the amylopectin and amylose exhibited no positive effect on protecting the breaking of the film. ${ }^{45}$ CSAPW had a smooth surface and micropores on it; moreover, starch hydrolysis on immersion in water destroyed the film surface and produced the pores (arrowheads in CSAPW of Fig. 4). A rough surface with bubble shaped bulges was observed, suggesting that the destruction of the film surface via hydrolysis allowed the escape of air or carbon dioxide on immersion in water (arrowheads in CSPW of Fig. 4). Clearly, the hydrolysis
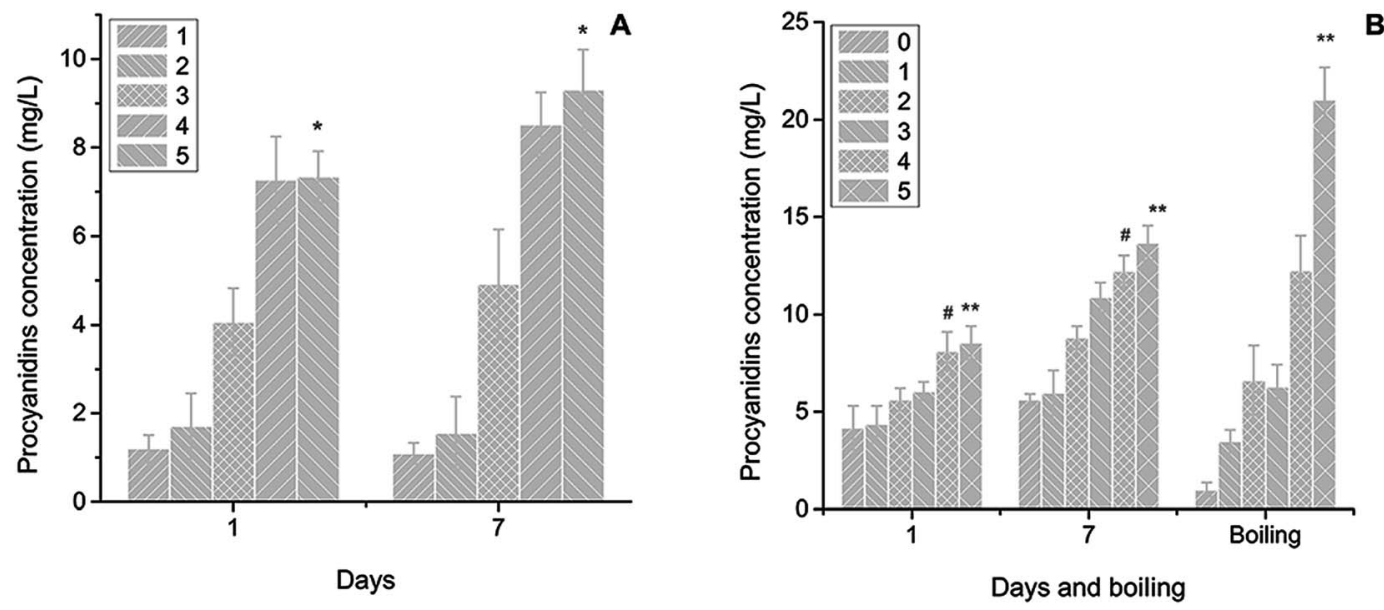

Fig. 2 Determination of procyanidins and $\alpha$-amylase content. (A) Determination of the addition amount of procyanidins solution. Lines of 1, 2, 3, 4 and 5 are volume of procyanidins solution ( $\mathrm{mL}$ ). (B) Determination of the addition amount of $\alpha$-amylase solution. Lines of 1, 2, 3, 4 and 5 are volume of $\alpha$-amylase solution $(\mathrm{mL})$. Same symbol represents significantly different values at $p \leq 0.05$. 

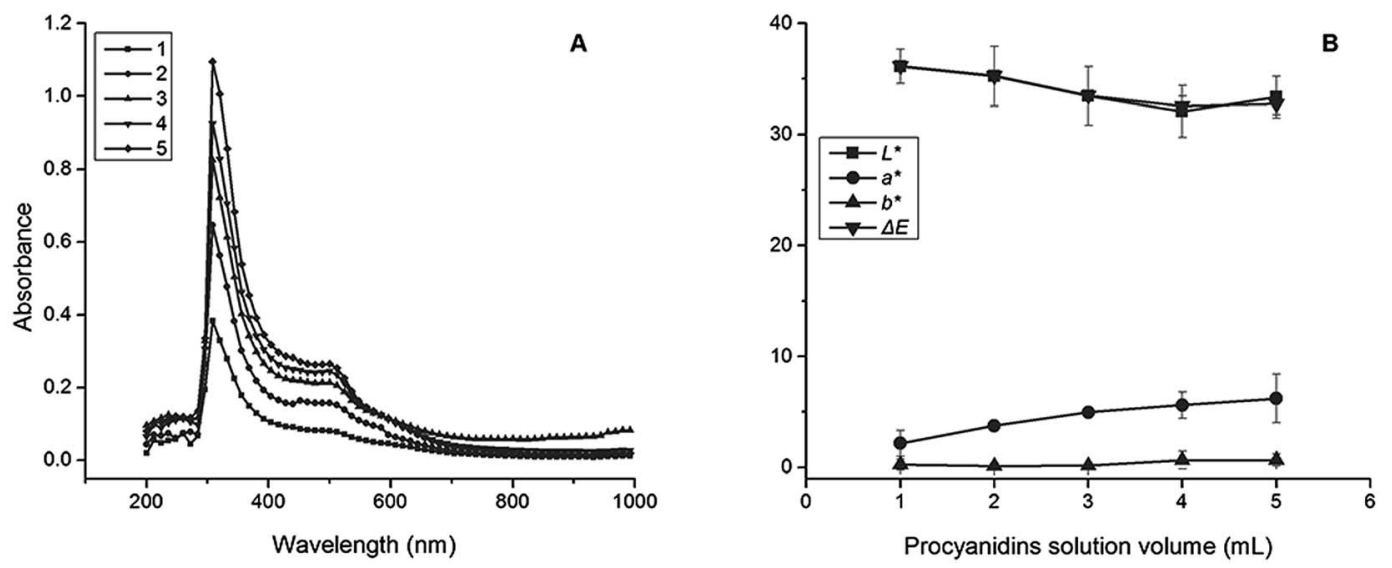

Fig. 3 Optical properties of films. (A) Colour coordinate. Lines of 1, 2, 3, 4 and 5 are volume of procyanidins solution (mL). (B) Full-wavelength scanning.

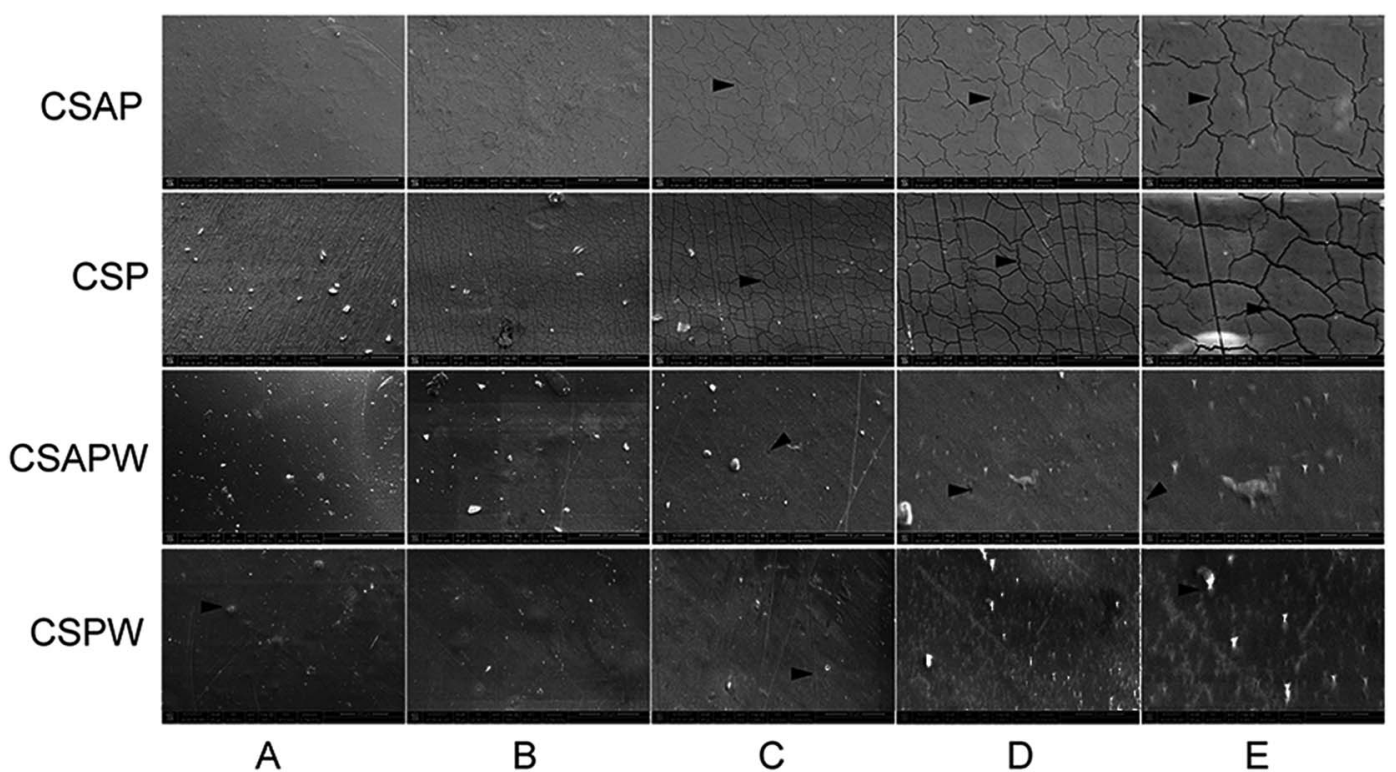

Fig. 4 Morphologies of films observed using SEM. Pictures of the first line are the morphologies of CSAP (film containing chitosan starch, $\alpha$ amylase and procyanidins). Pictures of the second line are the morphologies CSP (film containing by chitosan, starch and procyanidins). Pictures of the third line are the morphologies of CSAPW (film containing chitosan, starch, $\alpha$-amylase and procyanidins, and it was immersed in water for 7 days). Pictures of the third line are the morphologies of CSPW (film containing chitosan, starch and $\alpha$-amylase, and it was immersed in water for 7 days). The first, second, and third rows are pictures with 1000, 2000, and 4000 times magnification.

function also contributed to the escape of ingredients in film, such as the saccharide produced by starch hydrolysis and the procyanidins.

\subsection{XRD detection}

The rice starch powder had a typical diffraction pattern with strong reflection at four peaks with $2 \theta$ in the range of 16-24 (Fig. 5A). Chitosan powder was in a crystalline state because two main diffraction peaks at $2 \theta$ of approximately $12-20$ and the peak at $2 \theta$ of approximately 20 of disappeared and peaks at $2 \theta$ of approximately 12 still existed with less intensity. ${ }^{37} \mathrm{CS}$ and chitosan film subtracting the crystalline state of starch possessed similar peaks at $2 \theta$ of approximately 20 , and the addition of starch increased the crystal intensity. These results demonstrated that the interlinkage between chitosan and starch showed a positive effect on maintaining the crystal structure of chitosan and its film.

Procyanidins with visible peaks at $2 \theta$ of 19.92 and a step-like structure peak at $2 \theta$ in the range of $8.84-12.78$ of induced a slight change of the CS crystal structure at $2 \theta$ of approximately 11 (CSP and CSPW of Fig. 5B). Water immersion and dissolution of the procyanidins destroyed the crystal structure of the CSP film, which caused a strong decrease of CS typical peak at $2 \theta=$ 20 (CSPW of Fig. 5B). Water immersion resulted in the hydrolysis of starch and the release of procyanidins, which induced CSAP decrease (CSAPW of Fig. 5C). CSAPW and CSPW had 

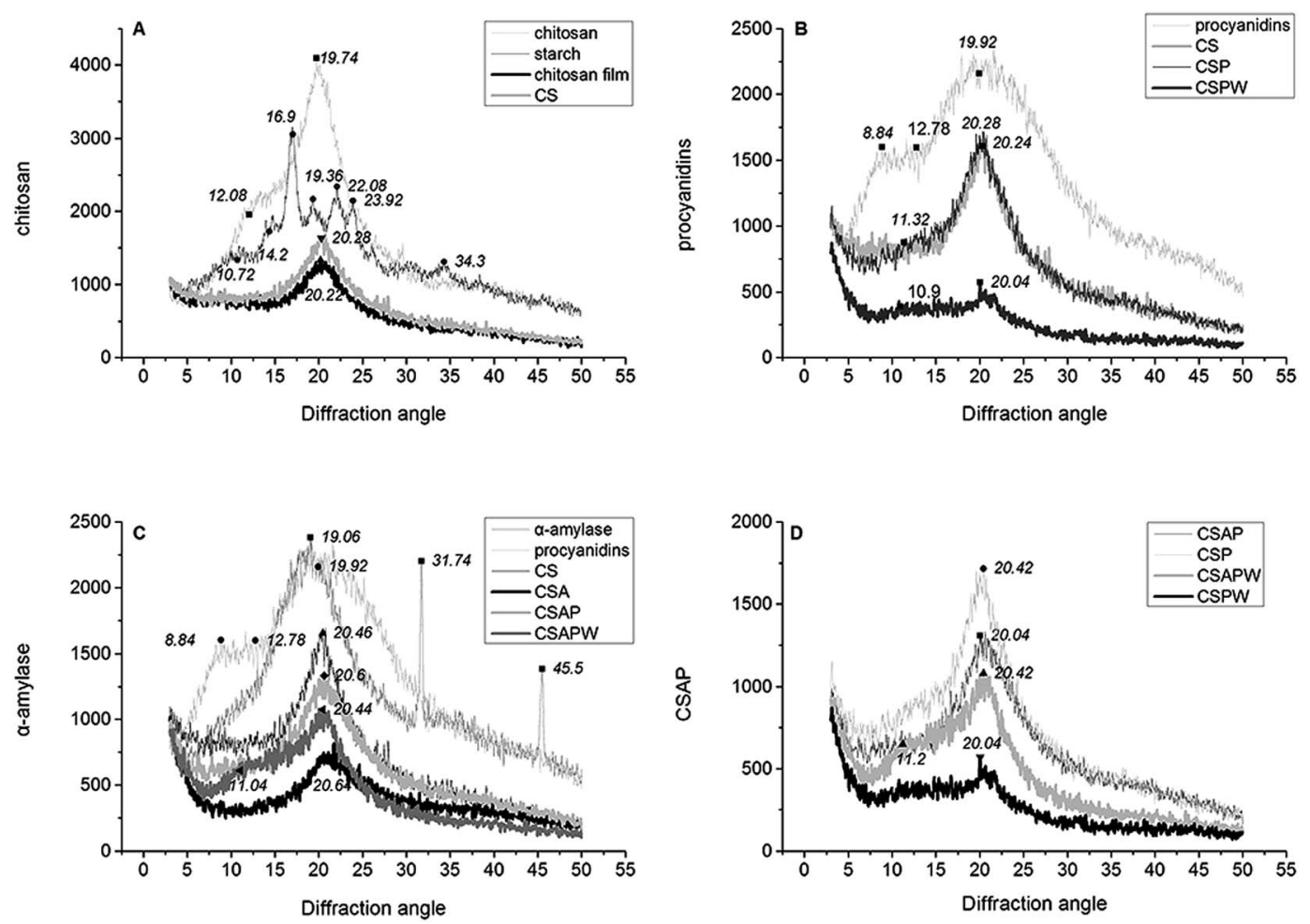

Fig. 5 XRD detection with combination of ingredients and films.

relatively higher crystal intensity than the other two lines at $2 \theta$ of approximately 11, and water also induced a significantly higher peak in CSAPW than others by releasing the starch and its hydrolysate (CSPW and CSAPW of Fig. 5D).

\subsection{Film stability determination by FT-IR spectra}

Absorption bands at approximately $1037 \mathrm{~cm}^{-1}$ (C-O stretching) and $1153 \mathrm{~cm}^{-1}$ (asymmetric stretching of $\mathrm{C}-\mathrm{O}-\mathrm{C}$ bridge and glycosidic linkage) were characteristics of its saccharide structure (Fig. 6A). ${ }^{43}$ The peaks at 1411, 1566 and $2929 \mathrm{~cm}^{-1}$ were assigned to the $\mathrm{C}-\mathrm{O}$ stretching of the $\mathrm{C}-\mathrm{O}-\mathrm{H}$ stretching of the primary alcoholic group $\left(-\mathrm{CH}_{2} \mathrm{OH}\right)$, the $\mathrm{C}-\mathrm{H}$ bending of $-\mathrm{CH}_{2}$ of the pyranose ring and $\mathrm{N}-\mathrm{H}$ bending in the primary amine groups $\left(-\mathrm{NH}_{2} /-\mathrm{NH}^{3+}\right)$, respectively. ${ }^{12,43,46}$ The bands at 1657 and $2929 \mathrm{~cm}^{-1}$ were attributed to $\mathrm{C}=\mathrm{O}$ stretching (amide) and the $\mathrm{C}-\mathrm{H}$ stretching related with the ring methane hydrogen atoms. ${ }^{47}$ The broad band occurring at $3356 \mathrm{~cm}^{-1}$ was attributed to the vibration stretching of bound $\mathrm{O}-\mathrm{H}$. The shift of chitosan and starch peaks at $3404 \mathrm{~cm}^{-1}$ to $3356 \mathrm{~cm}^{-1}$, and the change of $1656 \mathrm{~cm}^{-1}$ to $1567 \mathrm{~cm}^{-1}$ indicated the strong hydrogen bonding between the chitosan chain and chitosan starch. Procyanidins addition improved the vibration modes of CSAP to 1412, 1567 and $3325 \mathrm{~cm}^{-1}$ (Fig. 6B) as well as that of CSAPW, illustrating that procyanidins and polysaccharide were released in the water immersion.

The vibrational stretching of $\mathrm{O}-\mathrm{H}$ bond in CS was weaker than that of other groups, illustrating that the hydrogen bond between $\mathrm{O}-\mathrm{H}$ and $-\mathrm{NH}_{2}$ or $\mathrm{O}-\mathrm{H}$ and $\mathrm{O}-\mathrm{H}$ was rigid and restricted the vibrational stretching of O-H (Fig. 6C). Procyanidins enhanced the intensity of $\mathrm{O}-\mathrm{H}$ by interlinking the $\mathrm{O}-\mathrm{H}$ of the chitosan and phenolic hydroxyl groups, and the dissolution of procyanidins led to the decrease in the intensity of $-\mathrm{CH}_{2} \mathrm{OH}$ at $1411 \mathrm{~cm}^{-1}$ and $\mathrm{N}-\mathrm{H}$ at $1566 \mathrm{~cm}^{-1}$ by destroying the hydrogen bonds (CSPW of Fig. 6C). Stretching of $\mathrm{C}-\mathrm{O}$ at $1047 \mathrm{~cm}^{-1}, \mathrm{C}-\mathrm{O}-\mathrm{H}$ of $-\mathrm{CH}_{2} \mathrm{OH}$ at $1411 \mathrm{~cm}^{-1}, \mathrm{~N}-\mathrm{H}$ at $1562, \mathrm{O}-\mathrm{H}$ at $3325 \mathrm{~cm}^{-1}$ and $\mathrm{N}-\mathrm{H}$ bending in the primary amine groups $\left(-\mathrm{NH}_{2} /-\mathrm{NH}^{3+}\right)$ at $2906 \mathrm{~cm}^{-1}$ was significantly decreased by the $\alpha$-amylase. Water immersion plays an important role in this process by dissolving the procyanidins and saccharides (CSAPW and CSPW, Fig. 6D). Procyanidins and $\alpha$-amylase also enhanced the hydrogen link of $\mathrm{O}-\mathrm{H}$ at 3325 and $\mathrm{N}-\mathrm{H}$ bending in the primary amine groups $\left(-\mathrm{NH}_{2} /-\mathrm{NH}^{3+}\right)$ at $2906 \mathrm{~cm}^{-1}$, resulting in high intensity at those groups (Fig. 6D).

\subsection{Differential scanning calorimetry analysis}

The peaks' shapes in CSPW and CSAP were similar, and a sharper exothermic process was observed in CSAPW than the other three curves (Fig. 7). The decrease of four lines approximately at $100{ }^{\circ} \mathrm{C}$ was due to water evaporation. ${ }^{12}$ Starch hydrolysis and water immersion facilitated the escape of the hydrolyzate of starch and the procyanidins, leading to more space and binding sites of hydrogen bonds for water. This phenomenon resulted in more water permeating into CSAPW and a large area of peak observed in it. Starch hydrolysis in drying of CSAP and dissolution of starch and procyanidins of 

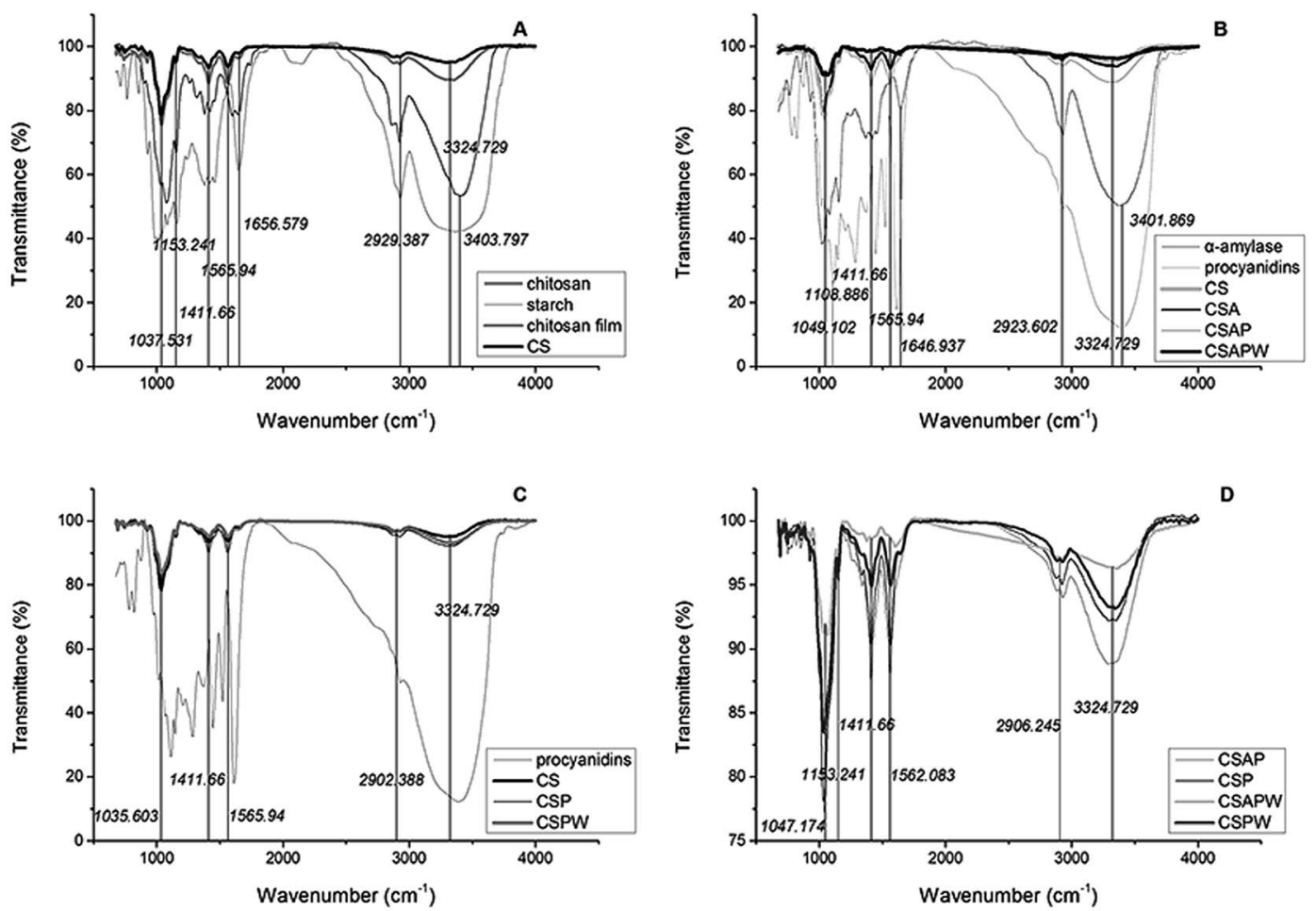

Fig. 6 Stability determination of combination of ingredients and films by FT-IR spectra.

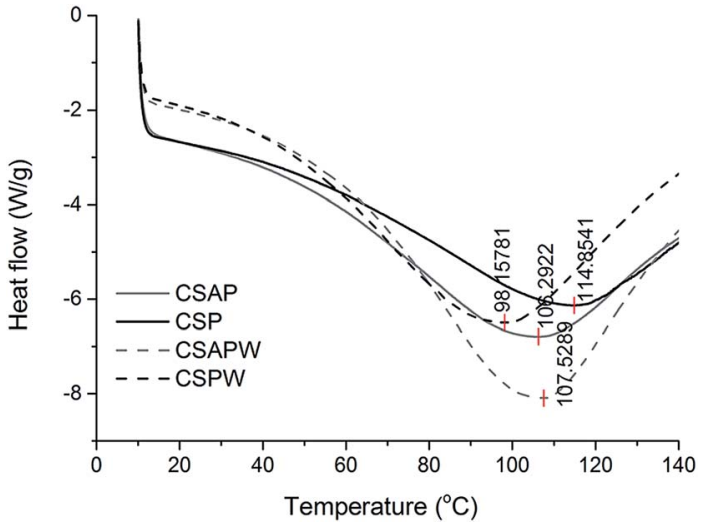

Fig. 7 DSC analysis of the four films.

CSPW in water immersion also had the same positive effect on increasing the hydrogen bonds for restricting the water in films. Therefore, the areas of CSAP and CSPW were larger than that in CSP (Fig. 7).

CSP with the highest water evaporation temperature exhibited the strongest water binding capacity by the linkage between the $\mathrm{O}-\mathrm{H},-\mathrm{NH}_{2}$ and phenolic hydroxyl groups. Moreover, the small space resulted in more combining sites for water molecule and restricted the water evaporation. CSPW had the lowest evaporation temperature at approximately $98.2{ }^{\circ} \mathrm{C}$. The sites of hydrogen bonds in CSAPW and CSAP exposed by the hydrolysis of $\alpha$-amylase exhibited strong ability in binding the water molecule than CSPW.

\section{Conclusions}

The film-forming solutions obtained the lowest $\mathrm{pH}=4.15$ with $1 \mathrm{~mL}$ sodium bicarbonate at the beginning of drying, and the $\mathrm{pH}$ increased according to an approximate linear shape. $\alpha$-Amylase activity maintained a relatively high level when the $\mathrm{pH}$ of the solvent was more than 4 . Moreover, 3 day storage showed no visible effect on decreasing the activity. The trend of procyanidin release amount generally improved by the increase in amount of procyanidin addition. However, the increase of $\alpha$-amylase addition can improve the release amount of procyanidins, particularly on addition of appropriate amount of $\alpha$-amylase (more than $3 \mathrm{~mL}$ ). The values of $a^{*}$ and $b^{*}$ showed the rising trend, and the $L^{*}$ and $\Delta E$ declined along with the increasing amount of procyanidin addition.

Micropores observed on CSAPW can be induced by starch hydrolysis in water immersion, which destroyed the film surface and produced the pores. Water immersion decreased the crystal texture of CSAPW and CSPW by dissolving the procyanidins, starch and starch hydrolysis. It also decreased the vibration of hydrogen bonds and its related groups by starch hydrolysis. CSPW maintained the lowest evaporation temperature at approximately $98.2{ }^{\circ} \mathrm{C}$, and water evaporation temperatures of CSAPW and CSAP were lower than CSP.

\section{Conflicts of interest}

There are no conflicts to declare. 


\section{Acknowledgements}

This work was supported by the Shandong Provincial Natural Science Foundation, China (ZR2017MC073).

\section{References}

1 X. C. Jia, S. Lai and H. Yang, Food Control, 2015, 53, 195-205.

2 Z. Song, F. Li, H. Guan, Y. Xu, Q. Fu and D. Li, Food Control, 2017, 74, 34-44.

3 A. M. Durango, N. F. F. Soares and N. J. Andrade, Food Control, 2006, 17, 336-341.

4 P. Suil, M. Kenneths and D. Paul, Meat Sci., 2010, 85, 493.

5 E. Velickova, E. Winkelhausen, S. Kuzmanova, V. D. Alves and M. Moldão-Martins, LWT-Food Sci. Technol., 2013, 52, 80-92.

6 C. Xiao, L. Zhu, W. Luo, X. Song and Y. Deng, Food Chem., 2010, 121, 1003-1009.

7 E. Genskowsky, L. A. Puente, J. A. Pérez-Álvarez, J. FernandezLopez, L. A. Muñoz and M. Viuda-Martos, LWT-Food Sci. Technol., 2015, 64, 1057-1062.

8 F. Liu, B. Qin, L. He and R. Song, Carbohydr. Polym., 2009, 78, 146-150.

9 X. L. Shen, J. M. Wu, Y. Chen and G. Zhao, Food Hydrocolloids, 2010, 24, 285-290.

10 F. M. Pelissari, M. V. Grossmann, F. Yamashita and E. A. Pineda, J. Agric. Food Chem., 2009, 57, 7499-7504.

11 E. Talón, K. T. Trifkovic, V. A. Nedovic, B. M. Bugarski, M. Vargas, A. Chiralt and C. González-Martínez, Carbohydr. Polym., 2017, 157, 1153.

12 S. Mathew and T. E. Abraham, Food Hydrocolloids, 2008, 22, 826-835.

13 H. R. Zhao, K. Wang, Y. Zhao and L. Q. Pan, Biomaterials, 2002, 23, 4459.

14 B. Blanco-Fernandez, M. I. Rial-Hermida, C. Alvarez-Lorenzo and A. Concheiro, J. Appl. Polym. Sci., 2013, 129, 626-635.

15 X. Z. Shu and K. J. Zhu, Int. J. Pharm., 2000, 201, 51-58.

16 V. Chandrasekar, J. N. Coupland and R. C. Anantheswaran, J. Food Sci., 2016, 81, E2503.

17 M. Fan and Q. Hu, Carbohydr. Res., 2009, 344, 944-947.

18 C. Li, Q. Han, Y. Guan and Y. Zhang, Soft Matter, 2014, 10, 8245.

19 X. Jiang, Y. Zhao and L. Hou, Carbohydr. Polym., 2016, 135, 191-198.

20 N. Köhler, V. Wray and P. Winterhalter, J. Chromatogr. A, 2008, 1177, 114-125.

21 A. Alejo-Armijo, N. Glibota, M. P. Frías, J. Altarejos, A. Gálvez, E. Ortega-Morente and S. Salido, Int. J. Food Sci. Technol., 2016, 52, 679.

22 M. J. Bak, V. L. Truong, H. S. Kang, M. Jun and W. S. Jeong, Oxid. Med. Cell. Longevity, 2013, 2013, 409321.

23 Z. P. Vila, L. Guerrero, M. Margalef, M. Quiñones, L. Arola, A. Arola-Arnal and B. Muguerza, Antihypertensive Effect and
Hepatic Lipid Improvement of Grape Seed Procyanidins in Cafeteria-Diet Rats, World Forum of Nutrition, At Reus, Tarragona, Spain, 2013, vol. 62(2), pp. 1-74.

24 A. M. Mendoza-Wilson, S. I. Castro-Arredondo and R. R. Balandrán-Quintana, Food Chem., 2014, 161, 155-161. 25 H. Falleh, S. Oueslati, S. Guyot, A. B. Dali, C. Magné, C. Abdelly and R. Ksouri, Food Chem., 2011, 127, 1732-1738. 26 H. Xie, S. Zhang and S. Li, Green Chem., 2006, 8, 630-633.

27 M. Zeng, Z. Fang and C. Xu, J. Membr. Sci., 2004, 230, 175181.

28 C. Pastor, L. Sánchez-González, A. Chiralt, M. Cháfer and C. González-Martínez, Food Hydrocolloids, 2013, 30, 272-280.

29 R. B. Toma and H. K. Leung, Food Chem., 1987, 23, 29-33.

30 L. J. Porter, L. N. Hrstich and B. G. Chan, Phytochemistry, 1985, 25, 223-230.

31 H. J. Yang, J. H. Lee, M. Won and K. B. Song, Food Chem., 2016, 196, 174-179.

32 W. Shujun, G. Wenyuan, L. Hongyan, C. Haixia, Y. Jiugao and X. Peigen, Food Chem., 2006, 99, 38-44.

33 A. Zarski, S. Ptak, P. Siemion and J. Kapusniak, Carbohydr. Polym., 2016, 137, 657-663.

34 O. Lopez, M. A. Garcia, M. A. Villar, A. Gentili, M. S. Rodriguez and L. Albertengo, LWT-Food Sci. Technol., 2014, 57, 106-115.

35 E. Taqieddin and M. Amiji, Biomaterials, 2004, 25, 19371945.

36 J. Zhu, Z. Zhu, Z. Lai, R. Wang, X. Guo, X. Wu, G. Zhang, Z. Zhang, Y. Wang and Z. Chen, Sensors, 2002, 2, 127-136.

37 T. Bourtoom and M. S. Chinnan, LWT-Food Sci. Technol., 2008, 41, 1633-1641.

38 S. Isabel, B. Sun, M. Anam, F. Vítorde and R. S. Jorgem, Food Chem., 2008, 108, 519-532.

39 M. Jerez, A. Selga, J. Sineiro, J. L. Torres and M. J. Nunez, Food Chem., 2007, 100, 439-444.

40 D. K. Asami, Y. J. Hong, D. M. Barrett and A. E. Mitchell, J. Sci. Food Agric., 2003, 83, 56-63.

41 V. Glavnik, B. Simonovska and I. Vovk, J. Planar Chromatogr.-Mod. TLC, 2010, 23, 230-232.

42 J. Mei, Y. Yuan, Y. Wu and Y. Li, Int. J. Biol. Macromol., 2013, 57, 17-21.

43 A. Silva-Weiss, V. Bifani, M. Ihl, P. J. A. Sobral and M. C. Gómez-Guillén, Food Hydrocolloids, 2013, 31, 458-466.

44 L. E. Abugoch, C. Tapia, M. C. Villamán, M. Yazdani-Pedram and M. Díaz-Dosque, Food Hydrocolloids, 2011, 25, 879-886.

45 M. A. Khan, M. A. Rahman, R. A. Khan, N. Rahman, J. M. M. Islam, R. Alam and M. I. H. Mondal, Polym.-Plast. Technol. Eng., 2010, 49, 748-756.

46 A. Sionkowska, A. Planecka, J. Kozlowska, J. SkopinskaWisniewska and P. Los, Carbohydr. Polym., 2011, 84, 900906.

47 Y. Zhong, X. Song and Y. Li, Carbohydr. Polym., 2011, 84, 335-342. 